\title{
Correction to: Drivers of HIV-1
}

\section{drug resistance to non-nucleoside} reverse-transcriptase inhibitors (NNRTIs) in nine southern African countries: a modelling study

Julien Riou ${ }^{1 *}$, Carole Dupont ${ }^{1}$, Silvia Bertagnolio², Ravindra K. Gupta ${ }^{3,4}$, Roger D. Kouyos ${ }^{5,6}$, Matthias Egger ${ }^{1,7,8}$ and Christian L. Althaus ${ }^{1}$

\section{Correction to: BMC Infect Dis (2021) 21:1042}

https://doi.org/10.1186/s12879-021-06757-6

Following publication of the original article [1], it was noted that the Supplementary file was missing.

Additional file 1 can be found in this Correction article (Additional file 1).

The original article has been corrected as well.

\section{Supplementary Information}

The online version contains supplementary material available at https://doi. org/10.1186/s12879-021-06791-4.

Additional file 1. Additional details about the data and the model.

\section{Author details}

${ }^{1}$ Institute of Social and Preventive Medicine (ISPM), University of Bern, Mittelstrasse 43, 3012 Bern, Switzerland. ${ }^{2}$ HIV/Hepatitis/STI Department, World Health Organization, Geneva, Switzerland. ${ }^{3}$ Department of Infection, University College London, London, UK. ${ }^{4}$ Africa Health Research Institute, Durban, South Africa. ${ }^{5}$ Division of Infectious Diseases and Hospital Epidemiology, University Hospital Zurich, Zurich, Switzerland. ${ }^{6}$ Institute of Medical Virology, University of Zurich, Zurich, Switzerland. ${ }^{7}$ Centre for Infectious Disease Epidemiology and Research (CIDER), University of Cape Town, Cap Town, South
Africa. ${ }^{8}$ Bristol Medical School, Population Health Sciences, University of Bristol, Bristol, UK.

Published online: 25 October 2021

\section{Reference}

1. Riou J, Dupont C, Bertagnolio S, Gupta RK, Kouyos RD, Egger M, Althaus CL. Drivers of HIV-1 drug resistance to non-nucleoside reversetranscriptase inhibitors (NNRTIs) in nine southern African countries: a modelling study. BMC Infect Dis. 2021;21:1042. https://doi.org/10.1186/ s12879-021-06757-6.

\section{Publisher's Note}

Springer Nature remains neutral with regard to jurisdictional claims in published maps and institutional affiliations. regulation or exceeds the permitted use, you will need to obtain permission directly from the copyright holder. To view a copy of this licence, visit http://creativecommons.org/licenses/by/4.0/. The Creative Commons Public Domain Dedication waiver (http://creativeco mmons.org/publicdomain/zero/1.0/) applies to the data made available in this article, unless otherwise stated in a credit line to the data. 